Erratum

\title{
Erratum to "Melatonin Suppresses the Expression of 45S Preribosomal RNA and Upstream Binding Factor and Enhances the Antitumor Activity of Puromycin in MDA-MB-231 Breast Cancer Cells"
}

\author{
Ji Hoon Jung, ${ }^{1}$ Eun Jung Sohn $\mathbb{D}^{1},{ }^{1}$ Eun Ah Shin, ${ }^{1}$ Duckgue Lee, ${ }^{1}$ \\ Bonglee Kim $\mathbb{D}^{1},{ }^{1}$ Deok-Beom Jung, ${ }^{1}$ Ji-Hyun Kim, ${ }^{1}$ Miyong Yun, ${ }^{1}$ Hyo-Jeong Lee, \\ Yong Koo Park, ${ }^{2}$ and Sung-Hoon Kim $\mathbb{D}^{1}$ \\ ${ }^{1}$ College of Oriental Medicine, Kyung Hee University, 1 Hoegi-dong, Dongdaemun-gu, Seoul 130-701, Republic of Korea \\ ${ }^{2}$ College of Medicine, Kyung Hee University, 1 Hoegi-dong, Dongdaemun-gu, Seoul 130-701, Republic of Korea
}

Correspondence should be addressed to Sung-Hoon Kim; sungkim7@khu.ac.kr

Received 2 July 2019; Accepted 4 July 2019; Published 21 July 2019

Copyright (c) 2019 Ji Hoon Jung et al. This is an open access article distributed under the Creative Commons Attribution License, which permits unrestricted use, distribution, and reproduction in any medium, provided the original work is properly cited.

In the article titled "Melatonin Suppresses the Expression of 45S Preribosomal RNA and Upstream Binding Factor and Enhances the Antitumor Activity of Puromycin in MDAMB-231 Breast Cancer Cells" [1], there was an error in Figure 3(a), where the fifth lane (Mcl-1) was mistakenly duplicated with the sixth lane (Cyclin D1), due to a production error. The correct figure is shown below. 


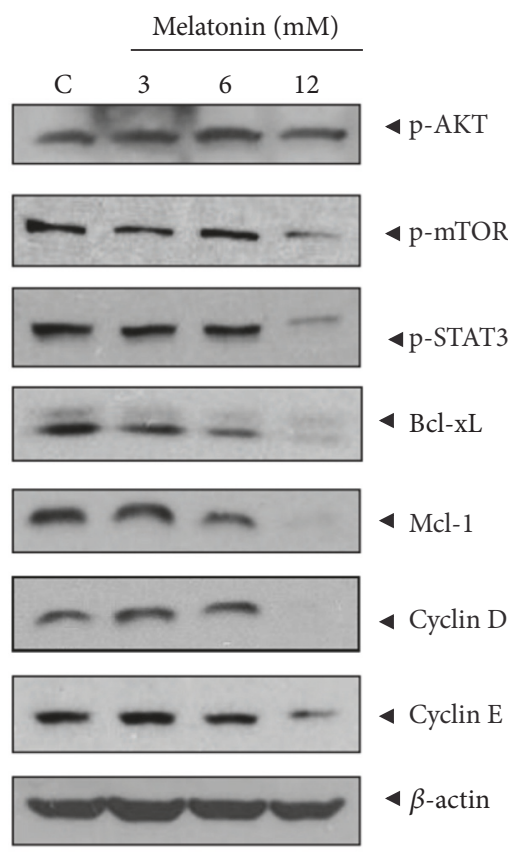

(a)

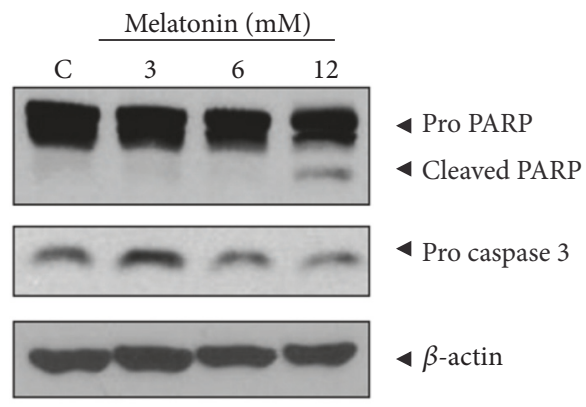

(b)

Figure 3: Effect of melatonin on the survival genes and apoptotic proteins in MDA-MB-231 cells. (a) Effect of melatonin on survival genes. (b) Effect of melatonin on procaspase 3 and PARP. Cells were treated with melatonin $(3 \mathrm{mM})$ for $24 \mathrm{~h}$. Western blotting analysis was performed with antibodies of above survival, apoptotic genes, and $\beta$-actin.

\section{References}

[1] J. H. Jung, E. J. Sohn, E. A. Shin et al., "Melatonin suppresses the expression of $45 \mathrm{~S}$ preribosomal RNA and upstream binding factor and enhances the antitumor activity of puromycin in MDA-MB-231 breast cancer cells," Evidence-Based Complementary and Alternative Medicine, vol. 2013, Article ID 879746, 8 pages, 2013. 


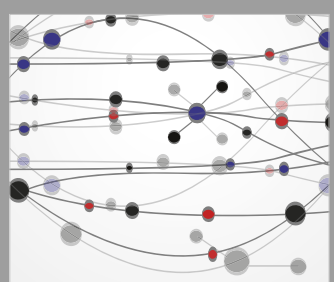

The Scientific World Journal
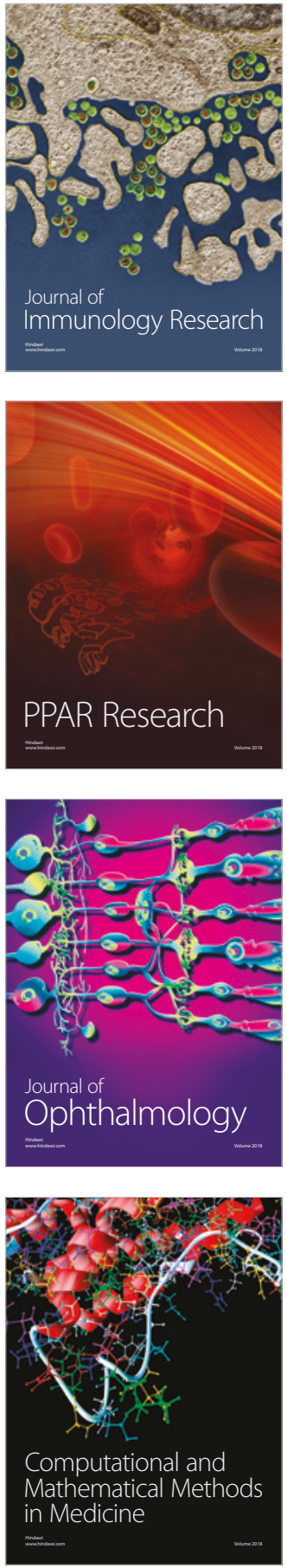

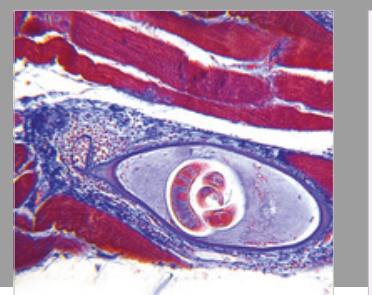

Gastroenterology Research and Practice

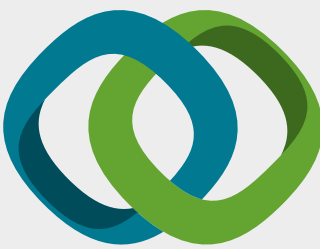

\section{Hindawi}

Submit your manuscripts at

www.hindawi.com
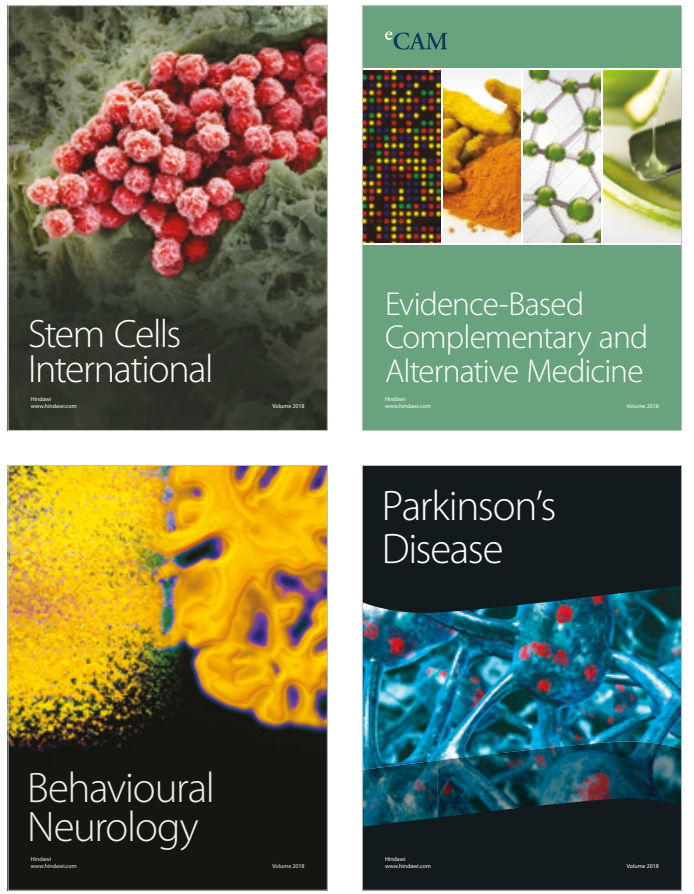

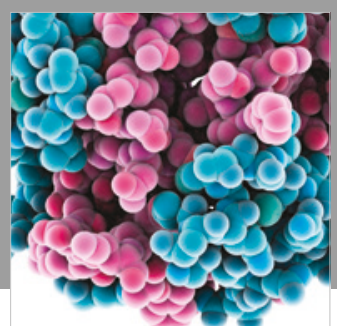

ournal of

Diabetes Research

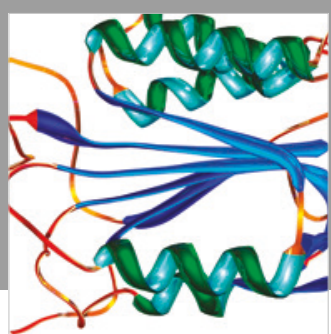

Disease Markers
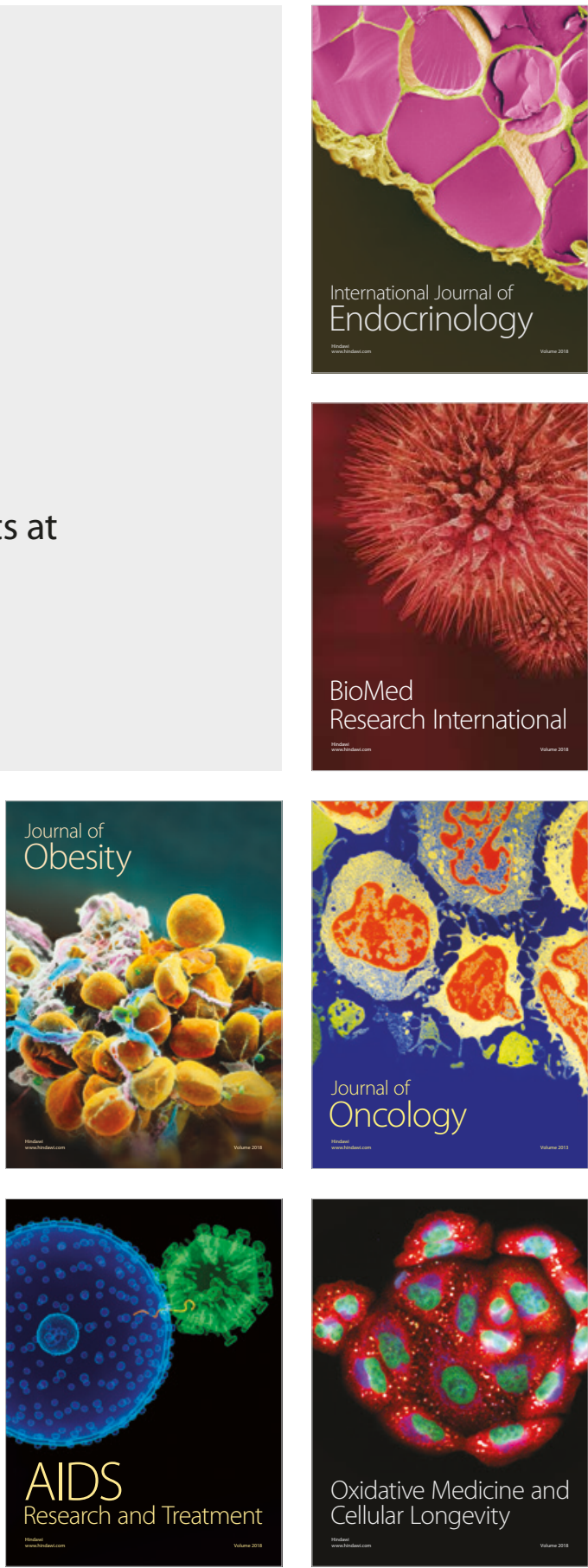